\title{
UNA SOCIEDAD EN LOS TIEMPOS DE HOY
}

\section{A Society in today's times}

La Sociedad de Cirujanos de Chile, en sus más de sesenta años de existencia, ha tenido y tiene una influencia significativa en los aspectos de desarrollo científico y técnico de la cirugía de nuestro país y de la Región.

Han existido iniciativas aisladas y que no fructificaron, como la de Quillón en Biobío en el año 2002 bajo la Presidencia del suscrito, para que nuestra Sociedad se involucrara en aspectos gremiales del ejercicio profesional de los cirujanos. En dicho momento, posiblemente no estaban aun dadas las condiciones ambientales y políticas para que ello fuese posible. Sin embargo, las semillas quedan y luego de un tiempo pueden dar sus frutos.

Si bien es cierto que la institución fue creada por los padres fundadores y así ha funcionado, como una entidad con fines cientificos, no existe hoy otra organización de los cirujanos chilenos que pueda representar mejor nuestras preocupaciones y nuestros intereses que esta. Ello es especialmente válido al pensar en las generaciones medianas y jóvenes, las que están enfrentadas a un mundo día a día más demandante, con empresas aseguradoras de salud y grandes prestadores institucionales cada vez más poderosos, que en la práctica imponen sus formas de ver y administrar la medicina, transformándose cada profesional en un insumo más. Pienso que una de las claves está en esto último, el enfrentamiento singular del problema; hemos presenciado agrupaciones médicas que han logrado posicionarse y hacerse respetar en regiones como la Quinta. ¿Por qué no podemos hacer lo mismo a nivel nacional?

Esta mirada gremial debe necesariamente tener un componente técnico que se preocupe de las condiciones de trabajo en hospitales, clínicas y centros de salud, con la implementación tecnológica y de personal apropiada a las condiciones de una salud moderna y exigente. Dirigido hacia esto se han dado algunos pasos en la última administración, incorporándose en los Congresos sesiones de análisis de los distintos servicios quirúrgicos del país.

Además, debe tener la mirada de una retribución médica justa y acorde con lo que hoy el medio social impone; ello implica lo económico y las facilidades de desarrollo y perfeccionamiento médico. Esto último se hace especialmente importante en los Centros Docentes, que posiblemente, dado el auge de las Facultades de Medicina y la necesidad de formación de especialistas, aumentarán hasta copar la gran mayoría de los centros asistenciales. Los médicos, en su doble labor asistencial y académica, deben contar con tiempos protegidos que les permitan realizar su tarea en forma responsable y con la calidad que ambas vertientes exigen.

Esta dimensión gremial, que complemente lo cientifico, es posible que además estimule la participación societaria de las generaciones emergentes de los cirujanos, los que hoy no ven clara la importancia o conveniencia de integrar nuestra Sociedad.

Dr. Julio Yarmuch $G$. Ex Presidente Sociedad de Cirujanos de Chile 